\title{
Técnicas, etiquetas y dispositivos de marcaje de prótesis dentales empleados en odontología forense como medio de identificación. Revisión sistemática de la literatura
}

\author{
Techniques, Labels, and Devices for Marking Dentures used \\ in Forensic Dentistry as a Means of Identification. Systematic \\ Review of the Literature
}

Sebastián Medina

Odontólogo, estudiante Maestría en Ciencias, Universidad del Valle, Cali, Colombia. Joven investigador, Colciencias 2012-2013.

Diego Vallejo

Odontólogo, profesor de la Escuela de odontología, Universidad de

Valle, Cali, Colombia. Especialista en Atención Integral del Adulto, Universidad de Antioquia, Medellín,

Colombia.

Freddy Moreno Gómez Odontólogo, magíster en Ciencias Biomédicas, profesor de la Escuela de Odontología, Universidad del

Valle, Cali, Colombia. Profesor, Departamento de Ciencias Básicas de la Salud, Pontificia Universidad Javeriana, Cali, Colombia.

CÓMO CITAR ESTE ARTÍCULO Medina S, Vallejo D, Moreno F. Técnicas, etiquetas y dispositivos de marcaje de prótesis dentales empleados en odontología forense como medio de identificación: revisión sistemática de la literatura. Univ Odontol. 2014 Jul-Dic; 33(71): http://dx.doi.org/10.11144/Javeriana.uo33-71.

tedm

doi:10.11144/Javeriana.uo33-71.tedm

Recibido para publicación: 01/08/2014 Aceptado para publicación: 13/07/2015

Disponible en: http://www.javeriana.edu.co/ universitasodontologica

\section{RESUMEN}

Antecedentes: producto de las múltiples formas y manifestaciones del ejercicio de la violencia, la identificación odontológica forense se puede dificultar por el estado del cuerpo o los restos humanos, tras la alteración de los tejidos blandos, la eliminación de las huellas digitales y la destrucción de los dientes. Además, existe la posibilidad particular de que un individuo sea edéntulo y que cuente con alternativas protésicas terapéuticas, lo que se interpreta como un obstáculo más. No obstante, es posible transformar esta condición en un eficaz método de reconocimiento a partir del marcaje de las prótesis dentales como medio de identificación. Propósito: evidenciar técnicas, etiquetas y dispositivos de marcaje de prótesis dentales y su utilidad durante los procesos de identificación odontológica y documentación médico-legal, para el caso de individuos edéntulos que se encuentren rehabilitados con prótesis dentales. Métodos: se realizó una revisión sistemática de la literatura a través de PubMed para obtener las publicaciones que describieran alguna técnica, etiqueta o dispositivo de marcaje empleado como medio de identificación dentro del contexto odontológico forense. Resultados: se obtuvieron 53 publicaciones que describen técnicas, etiquetas o dispositivos de marcaje de prótesis dentales que se han propuesto desde 1958. Conclusiones: el marcaje de prótesis dentales se constituye en un medio que proporciona información ante-post mórtem para guiar la identificación de un individuo o sus restos humanos. Sin embargo, se debe implementar un protocolo para estandarizar dichas técnicas, etiquetas y dispositivos, según criterios de permanencia, inalterabilidad, costo, lectura, biocompatibilidad y aceptación.

\section{PALABRAS CLAVE}

etiquetas de prótesis; identificación de la prótesis dental; identificación odontológica

\section{ÁREAS TEMÁTICAS}

Ciencias forenses; odontología forense

\section{ABSTRACT}

Background: As a result of the multiple manifestations of violence, dental forensic identification can be difficult to conduct due to the state of a body or human remains, caused by damage of soft tissues, removal of fingerprints, and tooth decay. There is also the possibility that the individuals are edentulous and wear dentures, which can be an obstacle. However, this condition can be solved by using effective denture labeling recognition methods for identification. Aim: To describe techniques, tags, and tagging devices of dentures and analyze their usefulness for dental forensic identification processes and medical-legal documentation in edentulous individuals who were rehabilitated with dentures. Methods: A systematic literature review was performed through PubMed of publications describing a technique, label, or marking device used as a means of identification within the dental forensic context. Results: 53 publications describing techniques, labels, or marking devices of dental prostheses, which have been introduced since 1958, were obtained. Conclusions: The marking of dentures provides ante-mortem information to guide the identification of individuals and/or their human remains. However, a protocol must implement to standardize these techniques, labels, and devices according to the criteria of permanence, immutability, cost, readability, biocompatibility, and acceptance.

\section{KEYWORDS}

dental identification; denture identification marking; marking dentures

\section{THEMATIC FIELDS}

Forensic dentistry; forensic science 


\section{INTRODUCCIÓN}

En países como Colombia, donde se vive una situación social y política compleja, las muertes violentas, las masacres, los ataques terroristas, la práctica generalizada de la desaparición forzada, la inhumación o cremación de los cuerpos en fosas comunes, entre otras manifestaciones de violencia (1) hacen que los procedimientos de identificación forense sean difíciles de llevar a cabo. Esto se debe, muchas veces, al estado de un cuerpo o de los restos humanos (avanzado estado de descomposición, mutilación, esqueletización, quemaduras, carbonización, incineración, entre otros), donde hay alteración de los tejidos blandos, destrucción o pérdida de los dientes, eliminación de las huellas digitales y mala calidad de las secuencias de ácido desoxirribonucleico (ADN) para ser interpretadas y analizadas (2).

Para esto, las instituciones encargadas del proceso de identificación deben contar con métodos eficaces que permitan el rápido reconocimiento de un individuo. Con este fin se han implementado diferentes elementos que sustituyen o complementan las características biológicas que hayan sido alteradas ante-, peri- o post mórtem. Uno de estos elementos resulta de las técnicas, las etiquetas y los dispositivos de marcaje de las prótesis dentales como medios de identificación (3).

Teniendo en cuenta la prevalencia de edentulismo y del uso de prótesis para remplazar morfofuncionalmente los dientes perdidos, es lógico que el empleo de diferentes técnicas, etiquetas y dispositivos de marcaje de dichas prótesis cumpla un papel fundamental dentro del contexto forense durante los procesos de identificación odontológica y documentación de la necropsia médico-legal (3). Infortunadamente, en Colombia la ley que unifica la dactiloscopia y que adopta la carta dental para fines de identificación (4) no se encuentra reglamentada, por lo que todos los métodos potenciales de identificación, que cuentan con evidencia técnica y científica sólida, no se implementan o son de registro obligatorio durante el ejercicio clínico de la odontología (5).

En el mundo, la prevalencia del edentulismo en personas mayores de 65 años de edad se encuentra entre el $7 \%$ y el $83 \%$. Es más frecuente en mujeres que en hombres, lo cual se atribuye principalmente a la caries dental y a las enfermedades periodontales. También se asocia a factores sociodemográficos como bajo nivel educativo y bajo ingreso familiar. En la literatura se han reportado tasas de edentulismo en Suecia (49-
$65 \%)$, Inglaterra (74-79\%), Escocia (85 \%), Irlanda (72 \%), Irlanda del Norte (69 \%), Países Bajos (83\%), Dinamarca (68\%), Finlandia (67\%), Noruega (57\%), Australia (68\%), Estados Unidos (25\%) y Canadá (22 \%) $(6-10)$.

En Colombia, la prevalencia de edentulismo en personas de 15 a 55 años de edad es del 48,1\% en el maxilar superior y del $53,6 \%$ en el maxilar inferior. No obstante, el uso de prótesis parciales o totales que remplacen los dientes perdidos es del $25,8 \%$ en el maxilar superior y del $7 \%$ en el maxilar inferior (11). Por tanto, y si bien es cierto que la prevalencia de edentulismo parcial y total es alta y las políticas de promoción y prevención en salud oral no evidencian cambios significativos en esta tendencia $(12,13)$, se puede asumir que, ante la ausencia de los dientes naturales y la imposibilidad de obtener información a partir de estos, el proceso de identificación odontológica puede aumentar su grado de dificultad. Por ello, el marcaje de las prótesis dentales resultaría fundamental para facilitar dicho proceso (3). El propósito de este estudio fue efectuar una revisión sistemática de la literatura para identificar las técnicas, las etiquetas y los dispositivos de marcaje de prótesis dentales y su utilidad en el contexto de las ciencias forenses, durante los procesos de identificación y documentación de la necropsia médico-legal, para el caso de pacientes parcial o totalmente edéntulos que se encuentren rehabilitados con prótesis dentales.

\section{Odontología forense}

A partir de las múltiples definiciones que existen en la literatura, la odontología forense se puede conceptualizar como una especialidad de la odontología que, a través del trabajo clínico, técnico y científico interdisciplinario, junto con las demás ciencias forenses, procura la recta administración de la justicia. Esto se hace teniendo en cuenta principios éticos y morales, y mediante la evidencia que ofrecen los dientes, estructuras anatómicas, patologías y tratamientos odontológicos, valorados durante la observación y análisis del sistema estomatognático por parte de los profesionales de la salud dentobucomaxilofacial. Se usa en casos de identificación de seres humanos vivos y fallecidos, dictámenes especiales, grandes desastres, exhumaciones, huellas de mordida, lesiones personales, maltrato infantil, abuso sexual y responsabilidad profesional (5,14-16).

\section{Identificación odontológica}

Los procesos de identificación de los seres humanos son de singular importancia en todas las sociedades 
pasadas y presentes, debido a que todos los individuos tienen una identidad en vida que debe ser constatada fehacientemente en el momento de la muerte con fines sociales, culturales, religiosos, judiciales, legales y económicos (15). En la investigación científicocriminalística de la muerte, el examen minucioso de los tejidos blandos y duros que conforman el sistema estomatognático integra la recolección, el análisis, la clasificación y la interpretación de la información por parte de investigadores, fiscales y peritos forenses (incluido el odontólogo). Todo este proceso permite obtener evidencia física que contribuye al establecimiento de la identidad de una persona (16).

La identificación positiva de una persona requiere la coincidencia fehaciente de las características físicas del fallecido (post mórtem) con los registros de esas mismas características antes de la muerte (ante mortem). En caso de cadáveres cuyo reconocimiento visual se dificulta, aun cuando no se pueden recuperar las huellas digitales, el sistema estomatognático proporciona características distintivas e indiciarias que permiten llegar a una identificación positiva a través de métodos odontológicos, antropológicos y análisis de $\operatorname{ADN}(17,18)$. Sin embargo, la información obtenida de la historia clínica odontológica, de acuerdo con el Consejo Estadounidense de Odontología Forense (19), se considera fundamental para realizar el cotejo dental ante-post mórtem y establecer la identidad positiva (coincidencia total), posible (compatibilidad), insuficiente (información disponible inadecuada) y exclusiva (incoherencia e incompatibilidad) en un caso determinado (20).

De igual forma, dicha información puede ser fehaciente (métodos científicos legales como resultado de la comparación de evidencias dubitadas e indubitadas), e indiciaria o complementaria (métodos no científicos como datos biográficos, antecedentes médicos, vestuario, documentos y señales particulares). A su vez, este proceso de identificación puede ser comparativo, al permitir el cotejo de los registros odontológicos ante mortem (historia clínica de los tratamientos odontológicos) y exámenes complementarios (radiografías, tomografías y modelos de estudio, entre otros) con los registros post mórtem (información que se obtiene del cadáver). El proceso también puede ser reconstructivo, al integrar el trabajo en equipo de odontólogos, antropólogos y morfólogos para realizar la reconstrucción facial y estimar la cuarteta básica de identificación u osteobiografía general (sexo, edad, patrón étnico y estatura) (1).

\section{Identificación de las prótesis dentales}

En la literatura especializada, desde 1931 se encuentra una gran cantidad de reportes que describen diversas técnicas, etiquetas y dispositivos de marcaje empleados en odontología forense como medios de identificación (21). Incluso, en algunos países como Estados Unidos, Islandia y Suecia es obligatorio el marcaje de las prótesis dentales parciales o totales removibles (22). Tal como se manifestó, la prevalencia de individuos edéntulos llega casi a ser la mitad de la población en algunos países, lo cual se puede constituir en un problema médico-legal en el caso de que un cadáver individuo o los restos de un ser humano queden afectados de tal manera que no sea posible establecer su identidad a partir del reconocimiento visual, del análisis de los dientes o de la obtención de las huellas digitales. En casos particulares como estos, las prótesis dentales cumplen un papel fundamental en un proceso de identificación comparativa, donde los registros ante mórtem que se obtienen a partir de la historia clínica odontológica (tipo de prótesis y forma, tamaño, número, color y marca de los dientes protésicos, y todos los exámenes complementarios como modelos de estudio, modelos de trabajo y radiografías) se pueden cotejar con los registros post mórtem obtenidos del sistema estomatognático y de las prótesis dentales, las cuales resisten condiciones extremas de acidez, alcalinidad, impacto y altas y bajas temperaturas, debido a los materiales en las que están confeccionadas (acrílicos, cerámicas y aleaciones metálicas) y a la protección que les confieren los tejidos blandos y la osteomusculatura craneofacial (20,23-26). Sin embargo, no siempre los profesionales de la salud dentobucomaxilofacial realizan historias clínicas exhaustivas o no todos los pacientes consultan profesionales certificados que registran los procedimientos odontológicos, lo cual reduce las posibilidades de obtener información fehaciente (27).

Por consiguiente, marcar e individualizar las prótesis dentales resulta esencial para apoyar los procesos de identificación forense y lograr el reconocimiento de un individuo o sus restos humanos. Para ello: a) una prótesis dental debe reunir suficientes marcadores únicos e irrepetibles que objetivamente conduzcan a una identificación positiva; b) las técnicas, las etiquetas y los dispositivos de marcaje deben consistir en un procedimiento versátil y de bajo costo llevado a cabo en el laboratorio dental donde se confeccionó la prótesis; c) los materiales empleados para confeccionar la marca deben ser resistentes al medio oral y a condiciones extremas (acidez, alcalinidad, impacto y altas y bajas temperaturas); d) la marca debe ser rea- 
lizada, preferiblemente, en la región palatina (prótesis superiores) o en la región lingual (prótesis inferiores), las cuales se encuentran protegidas por la bóveda palatina y por la lengua, respectivamente; e) el sitio de marcaje no debe afectar la solidez estructural, la estética, la durabilidad o las características morfofuncionales de la prótesis dental; f) la marca debe ser biológicamente estable, duradera, visible sin afectar la estructura de la prótesis y de recuperación inmediata (3,22,25-28). En la actualidad, aún no se ha reportado ninguna técnica cuya etiqueta o dispositivo cumpla con todos los requisitos mencionados (29).

\section{Tipos de técnicas, etiquetas y dispositivos de marcaje}

De acuerdo con lo reportado en la literatura, se han propuesto diferentes tipos de etiquetas y dispositivos para el marcaje de prótesis dentales, debido al potencial beneficio dentro de los procesos de identificación odontológica forense de un individuo o sus restos humanos. Estas etiquetas y dispositivos de marcaje se pueden clasificar en cuanto a la técnica desarrollada para elaborarlos. De esta forma, son agrupados en técnicas de marcado superficial y en técnicas de marcado por inclusión (25).

Las técnicas de marcado superficial consisten en la caracterización superficial del acrílico o del metal de una prótesis dental. Se han reportado diferentes técnicas que incluyen la escritura del nombre o códigos de identificación con marcadores de tintas insolubles en agua, que son de bajo costo, pero no se consideran permanentes por estar expuestas a la abrasión de los alimentos y a los elementos de higiene oral. Otra técnica es el grabado de bajo relieve del acrílico con objetos cortopunzantes (como bisturís o talladores) o rotatorios (fresas montadas en piezas de baja y alta velocidad). Esta técnica, si bien es más duradera, puede alterar la estética de una prótesis o comportarse como un sitio de retención de placa bacteriana y alimentos. Como respuesta a estos efectos indeseables, surgió la idea de grabar un bajo relieve (negativo) en el modelo de trabajo de yeso, para que de esta forma el acrílico lo copiara y quedara un alto relieve (positivo). Pero se reportó que se podría generar algún tipo de daño en la mucosa oral y que actuaría de igual forma como un sitio de retención de placa bacteriana y alimentos (30). Así mismo, ninguna de estas técnicas tiene la capacidad de resistir ambientes hostiles como medios ácidos o altas temperaturas (3).

Con respecto a las técnicas de marcado por inclusión, estas son las que más se han reportado, debido a la resistencia de los medios hostiles asociados a los materiales en que están confeccionados y al estar incluidos en el acrílico de las prótesis dentales. En estas técnicas, a la prótesis dental terminada y lista para ir a la cavidad oral del paciente se le realiza una cavidad en el componente acrílico en diferentes regiones que no afecten la resistencia, la adaptación y la estética. En dicha cavidad se incluye la etiqueta o dispositivo de marcado y, finalmente, se recubre con acrílico de autopolimerización del mismo color, lo que amplía el rango de permanencia de la etiqueta o dispositivo dentro de la prótesis (22). Si bien este método no cuenta con ninguna normativa de la Asociación Dental Estadounidense (ADA, por su sigla en inglés), aun cuando esta organización en 1985 diseñó un dispositivo de identificación de prótesis dentales con fines forenses (31), son organizaciones forenses como el Consejo Nacional de Salud y Bienestar de Suecia, el Departamento de Odontología Legal de Canadá, el Consejo Estadounidense de Odontología Forense, la Sociedad Estadounidense de Odontología Forense y la Organización Internacional de Odontoestomatología Forense las que localmente han reglamentado de alguna forma el proceso de marcaje de prótesis dentales (32).

Los materiales en los que se han elaborado las etiquetas incluyen papel, cintas plásticas, acetato y película fotográfica en negativo con el nombre del paciente o un código de identificación alfanumérico escrito a mano alzada con tinta indeleble o impreso digitalmente (22). Infortunadamente, estos métodos no han logrado resistir, por ejemplo, la acción de las altas temperaturas, pues se destruyen junto con las prótesis (3). Otro de los materiales empleados son placas o bandas metálicas a los cuales se les hace un grabado por serigrafía o pantografía láser con el nombre del paciente y un código alfanumérico. Este tipo de material ha contado con gran aceptación, dada la alta resistencia a medios hostiles como las altas temperaturas (3). Del mismo modo, se emplean códigos de barras y código 2D de barras que permiten ser leídos digitalmente para acceder casi inmediatamente a bases de datos en línea que no solo proveen el nombre o un código de identificación de un paciente, sino que permiten acceder, por ejemplo, a la historia clínica médica u odontológica de forma completa $(33,34)$.

No obstante, tienen las mismas desventajas de resistencia a las altas temperaturas, además de un costo elevado por el uso de dispositivos de lectura, conexión a internet y manejo de bases de datos (3). Con el mismo propósito anterior, existen dispositivos 
electrónicos de lectura tipo microchip que se emplean para acceder a sistemas de información con mayor protección (confidencialidad de la información) y con más capacidad de almacenamiento $(35,36)$. Sin embargo, el costo del dispositivo (microchip), del sistema de lectura (escáner) y de la base de datos (servidores) es elevado respecto del escaso beneficio, dada la baja resistencia y funcionabilidad del microchip a las altas temperaturas (3).

Finalmente, uno de los aspectos que más se han evaluado con respecto a las técnicas de marcaje de las prótesis dentales es la manera como el grabado o inclusión de las etiquetas y dispositivos puede afectar la estética de la prótesis. Hay varios reportes sobre creencias, prácticas y actitudes acerca de la percepción de los pacientes sobre el marcaje de las prótesis dentales, donde resultan favorecidas las técnicas de inclusión, siempre y cuando no afecten la resistencia, la adaptación y la estética de las prótesis. Por esa razón se argumenta que el marcaje debe realizarse en el laboratorio de prótesis dental (37-40).

\section{MATERIALES Y MÉTODOS}

Se realizó una revisión sistemática de la literatura en PubMed (motor de búsqueda de libre acceso a la base de datos Medline de la Biblioteca Nacional de
Medicina de Estados Unidos). Se usó como término de búsqueda denture identification marking, el cual fue localizado en el Medical Subject Headings. Se tuvieron en cuenta las publicaciones que presentaran y describieran alguna técnica, etiqueta o dispositivo de marcaje de prótesis dentales, cuyo propósito fuera constituirse en un medio de identificación dentro del contexto odontológico forense.

\section{RESULTADOS}

En total se incluyeron 53 publicaciones que cumplieron con los criterios de inclusión. Se organizaron por año de publicación, tipo de estudio, objetivo de la publicación y técnica, etiqueta o dispositivo empleado (tabla 1). De esta forma, se analizaron 38 artículos que corresponden a reportes en los que los autores describen específicamente una técnica, etiqueta o dispositivo de marcaje de prótesis dentales (figura 1). Hubo 3 estudios descriptivos sobre la prevalencia del uso de prótesis marcadas y 11 estudios descriptivos de diseño cuasi experimental en los que se evalúa la resistencia a la compresión, a la tensión, a la humedad y a las altas temperaturas de las diferentes técnicas, etiquetas y dispositivos empleados. También se incluyó un ensayo clínico que compara la resistencia de una técnica de marcaje superficial de prótesis dentales con y sin recubrimiento con resina acrílica.

TABLA 1

ESTUDIOS PUBLICADOS EN PUBMED SOBRE TÉCNICAS, ETIQUETAS Y DISPOSITIVOS EMPLEADOS EN LOS PROCESOS DE IDENTIIICACIÓN ODONTOLÓGICA FORENSE

\begin{tabular}{|c|c|c|c|c|}
\hline $\begin{array}{l}\text { Autores y } \\
\text { referencia }\end{array}$ & Año & $\begin{array}{c}\text { Tipo de } \\
\text { estudio y diseño }\end{array}$ & Propósito & $\begin{array}{c}\text { Técnica, etiqueta } \\
\text { o dispositivo }\end{array}$ \\
\hline Lose (41) & 1958 & $\begin{array}{l}\text { Descriptivo } \\
\text { reporte de caso }\end{array}$ & $\begin{array}{l}\text { Presentación de una técnica de inclusión } \\
\text { de una etiqueta de papel impresa para } \\
\text { marcaje por inclusión en prótesis de } \\
\text { acrílico }\end{array}$ & $\begin{array}{l}\text { Etiqueta de papel impresa } \\
\text { con un código de } \\
\text { identificación }\end{array}$ \\
\hline $\begin{array}{l}\text { Todo y } \\
\text { Lukens (42) }\end{array}$ & 1977 & $\begin{array}{l}\text { Descriptivo } \\
\text { reporte de caso }\end{array}$ & $\begin{array}{l}\text { Presentación de una técnica de inclusión } \\
\text { de una etiqueta de papel impresa para } \\
\text { marcaje por inclusión en prótesis de } \\
\text { acrílico }\end{array}$ & $\begin{array}{l}\text { Etiqueta de papel impresa } \\
\text { con nombre del paciente }\end{array}$ \\
\hline $\begin{array}{l}\text { MacEntee } \\
\text { y Campbell } \\
\text { (43) }\end{array}$ & 1979 & $\begin{array}{l}\text { Descriptivo } \\
\text { reporte de caso }\end{array}$ & $\begin{array}{l}\text { Presentación de una técnica de inclusión } \\
\text { de una etiqueta metálica impresa para } \\
\text { marcaje por inclusión en prótesis de } \\
\text { acrílico }\end{array}$ & $\begin{array}{l}\text { Etiqueta metálica impresa } \\
\text { con un código de } \\
\text { identificación }\end{array}$ \\
\hline Thomas (44) & 1980 & $\begin{array}{l}\text { Descriptivo } \\
\text { reporte de caso }\end{array}$ & $\begin{array}{l}\text { Presentación de una técnica de inclusión } \\
\text { de una etiqueta de metal impresa para } \\
\text { marcaje por inclusión en prótesis de } \\
\text { acrílico }\end{array}$ & $\begin{array}{l}\text { Etiqueta de metal } \\
\text { impresa con un código de } \\
\text { identificación ID-Band }\end{array}$ \\
\hline
\end{tabular}




\begin{tabular}{|c|c|c|c|c|}
\hline $\begin{array}{l}\text { Autores y } \\
\text { referencia }\end{array}$ & Año & $\begin{array}{c}\text { Tipo de } \\
\text { estudio y diseño }\end{array}$ & Propósito & $\begin{array}{c}\text { Técnica, etiqueta } \\
\text { o dispositivo }\end{array}$ \\
\hline ADA $(45,46)$ & 1982 & $\begin{array}{l}\text { Descriptivo } \\
\text { reporte de caso }\end{array}$ & $\begin{array}{l}\text { Presentación de una técnica de marcaje } \\
\text { de un microdisco acrílico cementado en } \\
\text { la superficie vestibular del primer molar }\end{array}$ & $\begin{array}{l}\text { Etiqueta de acrílico con un } \\
\text { código de identificación } \\
\text { grabado }\end{array}$ \\
\hline
\end{tabular}

\begin{tabular}{lrl}
$\begin{array}{l}\text { Johanson y } \\
\text { Ekman (47) }\end{array}$ & 1984 & $\begin{array}{l}\text { Descriptivo } \\
\text { reporte de caso }\end{array}$ \\
$\begin{array}{l}\text { Luebke y } \\
\text { Unsicker } \\
(48)\end{array}$ & 1985 & $\begin{array}{l}\text { Descriptivo } \\
\text { reporte de caso }\end{array}$ \\
$\begin{array}{l}\text { Dippenar } \\
\text { (49) }\end{array}$ & 1986 & $\begin{array}{l}\text { Descriptivo } \\
\text { reporte de caso }\end{array}$ \\
\hline $\begin{array}{l}\text { Chalian y } \\
\text { cols. (50) }\end{array}$ & 1986 & $\begin{array}{l}\text { Descriptivo } \\
\text { reporte de caso }\end{array}$ \\
\hline
\end{tabular}

Presentación de una técnica de inclusión de una etiqueta de metal impresa para marcaje por inclusión en prótesis de acrílico

Presentación de una técnica de inclusión

de una etiqueta plástica impresa para

marcaje por inclusión en prótesis de

acrílico

Presentación de una técnica de inclusión

de una etiqueta metálica impresa y

enrolladla para marcaje por inclusión en

prótesis de acrílico

Presentación de una técnica de inclusión

de una etiqueta de papel impresa incluida

en una barra de resina acrílica para

marcaje de prótesis acrílica

Fiske y cols. 1986 Descriptivo (51) reporte de caso

\begin{tabular}{lrl} 
Young (52) & 1987 & $\begin{array}{l}\text { Descriptivo } \\
\text { reporte de caso }\end{array}$ \\
$\begin{array}{lll}\text { Stevenson } \\
\text { (53) }\end{array}$ & 1987 & $\begin{array}{l}\text { Descriptivo } \\
\text { reporte de caso }\end{array}$ \\
\hline Heat (54) & 1987 & $\begin{array}{l}\text { Descriptivo } \\
\text { reporte de caso }\end{array}$
\end{tabular}

\begin{tabular}{lrl} 
Heath y cols. & 1988 & Ensayo clínico \\
(55) & & \\
Toolson y & 1989 & $\begin{array}{l}\text { Descriptivo } \\
\text { reporte de caso }\end{array}$ \\
\hline Taylor (56) & & repre
\end{tabular}

\section{Presentación de una técnica de grabado} manual con tinta convencional sobre un surco para marcaje por inclusión en prótesis de acrílico

Presentación de una técnica de grabado
manual con tinta sobre un surco para marcaje por inclusión en prótesis de acrílico

Presentación de una técnica de marcaje de prótesis mediante el grabado superficial del acrílico con bisturí

Presentación de una técnica de marcaje de prótesis mediante el grabado superficial del acrílico con tinta indeleble

Evaluación de una técnica de marcaje de prótesis mediante el grabado superficial del acrílico con tinta indeleble con recubrimiento y sin este

Presentación de una técnica de inclusión de una etiqueta plástica impresa para marcaje por inclusión en prótesis de acrílico
Etiqueta de metal impresa con un código de identificación ID-Band

Etiqueta de plástico impresa con un código de identificación

\section{Etiqueta de metal} enrollada impresa con un código de identificación

Barra de resina acrílica fotopolimerizable con forma de $T$ con etiqueta de papel impresa con un código de identificación

Grabado con tinta convencional en un surco en el acrílico posteriormente recubierto con resina acrílica transparente

Grabado con tinta en un surco en el acrílico posteriormente recubierto con resina acrílica transparente Grabado superficial con bisturí

Grabado superficial con tinta indeleble recubierta con resina acrílica transparente Grabado superficial con tinta indeleble recubierta con resina acrílica transparente Etiqueta plástica impresa con un código de identificación 


\begin{tabular}{|c|c|c|c|c|}
\hline $\begin{array}{l}\text { Autores y } \\
\text { referencia }\end{array}$ & Año & $\begin{array}{c}\text { Tipo de } \\
\text { estudio y diseño }\end{array}$ & Propósito & $\begin{array}{c}\text { Técnica, etiqueta } \\
\text { o dispositivo }\end{array}$ \\
\hline Oliver (57) & 1989 & $\begin{array}{l}\text { Descriptivo } \\
\text { reporte de caso }\end{array}$ & $\begin{array}{l}\text { Presentación de una técnica de inclusión } \\
\text { de una etiqueta de polimetilmetacrilato } \\
\text { impresa para marcaje por inclusión en } \\
\text { prótesis de acrílico }\end{array}$ & $\begin{array}{l}\text { Etiqueta de } \\
\text { polimetilmetacrilato } \\
\text { impresa con un código de } \\
\text { identificación }\end{array}$ \\
\hline $\begin{array}{l}\text { Gladfelter y } \\
\text { Smith (45) }\end{array}$ & 1989 & $\begin{array}{l}\text { Descriptivo cuasi } \\
\text { experimental }\end{array}$ & $\begin{array}{l}\text { Determinar la resistencia al medio } \\
\text { húmedo de microdiscos de poliéster } \\
\text { adheridos a la superficie de los dientes } \\
\text { con cementos adhesivos a base de resina }\end{array}$ & $\begin{array}{l}\text { Discos de poliéster } \\
\text { adheridos a la superficie } \\
\text { dental }\end{array}$ \\
\hline Hansen (46) & 1991 & $\begin{array}{l}\text { Descriptivo cuasi } \\
\text { experimental }\end{array}$ & $\begin{array}{l}\text { Determinar la resistencia al medio } \\
\text { húmedo de microdiscos de poliéster y de } \\
\text { acero inoxidable adheridos a la superficie } \\
\text { de los dientes con cementos adhesivos a } \\
\text { base de resina }\end{array}$ & $\begin{array}{l}\text { Discos de poliéster y de } \\
\text { acero inoxidable (grabados } \\
\text { con láser) adheridos a la } \\
\text { superficie dental }\end{array}$ \\
\hline Lamb (58) & 1992 & $\begin{array}{l}\text { Descriptivo } \\
\text { reporte de caso }\end{array}$ & $\begin{array}{l}\text { Presentación de una técnica de inclusión } \\
\text { de una etiqueta de polimetilmetacrilato } \\
\text { impresa y recubierta por dos laminillas } \\
\text { de vidrio para marcaje por inclusión en } \\
\text { prótesis de acrílico }\end{array}$ & $\begin{array}{l}\text { Etiqueta de } \\
\text { polimetilmetacrilato } \\
\text { impresa con un código de } \\
\text { identificación y recubierta } \\
\text { por dos laminillas de vidrio }\end{array}$ \\
\hline $\begin{array}{l}\text { Olsson y } \\
\text { cols. (59) }\end{array}$ & 1993 & $\begin{array}{l}\text { Descriptivo cuasi } \\
\text { experimental }\end{array}$ & $\begin{array}{l}\text { Determinar la resistencia a las altas } \\
\text { temperaturas de placas de acero } \\
\text { inoxidable incluidas en prótesis de acrílico }\end{array}$ & $\begin{array}{l}\text { Placas de acero inoxidable } \\
\text { ID-Band, Jash y Remanit, } \\
\text { etiquetadas con códigos } \\
\text { de identificación }\end{array}$ \\
\hline Ling (60) & 1993 & $\begin{array}{l}\text { Descriptivo } \\
\text { reporte de caso }\end{array}$ & $\begin{array}{l}\text { Presentación de una técnica de inclusión } \\
\text { de una etiqueta de papel seda impresa } \\
\text { en tinta convencional para marcaje por } \\
\text { inclusión en prótesis de acrílico }\end{array}$ & $\begin{array}{l}\text { Etiqueta de papel } \\
\text { seda impresa en tinta } \\
\text { convencional con un } \\
\text { código de identificación }\end{array}$ \\
\hline $\begin{array}{l}\text { Ryan y cols. } \\
\text { (61) }\end{array}$ & 1993 & $\begin{array}{l}\text { Descriptivo } \\
\text { reporte de caso }\end{array}$ & $\begin{array}{l}\text { Presentación de una técnica de inclusión } \\
\text { de una etiqueta de papel impresa incluida } \\
\text { en una barra de resina acrílica para } \\
\text { marcaje de prótesis acrílica }\end{array}$ & $\begin{array}{l}\text { Barra de resina acrílica } \\
\text { fotopolimerizable con } \\
\text { forma de T con etiqueta } \\
\text { de papel impresa con un } \\
\text { código de identificación }\end{array}$ \\
\hline $\begin{array}{l}\text { Borrman y } \\
\text { cols. (62) }\end{array}$ & 1995 & $\begin{array}{l}\text { Descriptivo cuasi } \\
\text { experimental }\end{array}$ & $\begin{array}{l}\text { Determinar la resistencia a la tracción y a } \\
\text { las altas temperaturas de placas de acero } \\
\text { inoxidable incluidas en prótesis de acrílico }\end{array}$ & $\begin{array}{l}\text { Placas de acero inoxidable } \\
\text { ID-Band, etiquetadas con } \\
\text { códigos de identificación }\end{array}$ \\
\hline $\begin{array}{l}\text { Thomas y } \\
\text { cols. (63) }\end{array}$ & 1995 & $\begin{array}{l}\text { Descriptivo cuasi } \\
\text { experimental }\end{array}$ & $\begin{array}{l}\text { Determinar la resistencia a la tracción y a } \\
\text { las altas temperaturas de placas de acero } \\
\text { inoxidable incluidas en prótesis de acrílico }\end{array}$ & $\begin{array}{l}\text { Placas de acero inoxidable } \\
\text { ID-Band, placas de } \\
\text { titanio y placas de acero } \\
\text { inoxidable Ho Band }\end{array}$ \\
\hline $\begin{array}{l}\text { Berry y cols. } \\
(64)\end{array}$ & 1995 & $\begin{array}{l}\text { Descriptivo } \\
\text { reporte de caso }\end{array}$ & $\begin{array}{l}\text { Presentación de una técnica de inclusión } \\
\text { de una etiqueta de papel impresa para } \\
\text { marcaje por inclusión en prótesis de } \\
\text { acrílico }\end{array}$ & $\begin{array}{l}\text { Etiqueta de papel } \\
\text { impresa con un código } \\
\text { de identificación, incluida } \\
\text { en un surco de } 1 \mathrm{~mm} \text { y } \\
\text { recubierta con resina } \\
\text { acrílica transparente }\end{array}$ \\
\hline $\begin{array}{l}\text { Coss y } \\
\text { Wolfaardt } \\
(65)\end{array}$ & 1995 & $\begin{array}{l}\text { Descriptivo } \\
\text { reporte de caso }\end{array}$ & $\begin{array}{l}\text { Presentación de una técnica de inclusión } \\
\text { de una etiqueta P-Touch } 300 \text { impresa } \\
\text { para marcaje por inclusión en prótesis de } \\
\text { acrílico }\end{array}$ & $\begin{array}{l}\text { Etiqueta P-Touch } 300 \\
\text { impresa con un código de } \\
\text { identificación y recubierta } \\
\text { con resina acrílica } \\
\text { transparente }\end{array}$ \\
\hline
\end{tabular}




\begin{tabular}{|c|c|c|c|c|}
\hline $\begin{array}{l}\text { Autores y } \\
\text { referencia }\end{array}$ & Año & $\begin{array}{c}\text { Tipo de } \\
\text { estudio y diseño }\end{array}$ & Propósito & $\begin{array}{l}\text { Técnica, etiqueta } \\
\text { o dispositivo }\end{array}$ \\
\hline $\begin{array}{l}\text { Bengston y } \\
\text { cols. (66) }\end{array}$ & 1996 & $\begin{array}{l}\text { Descriptivo } \\
\text { observacional }\end{array}$ & $\begin{array}{l}\text { Determinar la prevalencia del uso de } \\
\text { prótesis acrílicas etiquetadas con códigos } \\
\text { con fines de identificación del paciente } \\
\text { incluidas en prótesis de acrílico }\end{array}$ & $\begin{array}{l}\text { Placas de acero inoxidable } \\
\text { ID-Band etiquetadas con } \\
\text { códigos de identificación }\end{array}$ \\
\hline $\begin{array}{l}\text { Milward y } \\
\text { cols. }(67)\end{array}$ & 1997 & $\begin{array}{l}\text { Descriptivo } \\
\text { reporte de caso }\end{array}$ & $\begin{array}{l}\text { Presentación de una técnica de marcaje } \\
\text { de prótesis mediante el grabado de } \\
\text { estructuras cerámicas y acrílicas con } \\
\text { láser }\end{array}$ & $\begin{array}{l}\text { Grabado superficial de } \\
\text { códigos de barras }\end{array}$ \\
\hline $\begin{array}{l}\text { Bernitzh y } \\
\text { Blignaut (68) }\end{array}$ & 1998 & $\begin{array}{l}\text { Descriptivo cuasi } \\
\text { experimental }\end{array}$ & $\begin{array}{l}\text { Determinar la resistencia al desgaste de } \\
\text { una etiqueta impresa incluida en prótesis } \\
\text { de acrílico }\end{array}$ & $\begin{array}{l}\text { Etiqueta P-Touch } 300 \\
\text { impresa con un código de } \\
\text { identificación }\end{array}$ \\
\hline $\begin{array}{l}\text { Stenberg } \\
\text { y Borrman } \\
\text { (69) }\end{array}$ & 1998 & $\begin{array}{l}\text { Descriptivo } \\
\text { observacional }\end{array}$ & $\begin{array}{l}\text { Determinar la prevalencia del uso de } \\
\text { prótesis acrílicas etiquetadas con códigos } \\
\text { con fines de identificación del paciente } \\
\text { incluidas en prótesis de acrílico }\end{array}$ & $\begin{array}{l}\text { Placas de acero inoxidable } \\
\text { ID-Band y placas de } \\
\text { titanio, etiquetadas con } \\
\text { códigos de identificación }\end{array}$ \\
\hline Ibrahim (70) & 1998 & $\begin{array}{l}\text { Descriptivo } \\
\text { reporte de caso }\end{array}$ & $\begin{array}{l}\text { Presentación de una técnica de inclusión } \\
\text { de una etiqueta de acetato fotográfico de } \\
35 \mathrm{~mm} \text { impresa para marcaje por inclusión } \\
\text { en prótesis de acrílico }\end{array}$ & $\begin{array}{l}\text { Etiqueta de acetato } \\
\text { fotográfico de } 35 \mathrm{~mm} \text { con } \\
\text { un código de identificación }\end{array}$ \\
\hline Ling (71) & 1998 & $\begin{array}{l}\text { Descriptivo } \\
\text { reporte de caso }\end{array}$ & $\begin{array}{l}\text { Presentación de una técnica de inclusión } \\
\text { de una etiqueta de acetato impresa y } \\
\text { recubierta con cianoacrilato para marcaje } \\
\text { por inclusión en prótesis de acrílico }\end{array}$ & $\begin{array}{l}\text { Etiqueta de acetato } \\
\text { impresa con un código de } \\
\text { identificación y recubierta } \\
\text { con cianoacrilato }\end{array}$ \\
\hline $\begin{array}{l}\text { Rötzscher y } \\
\text { cols. (72) }\end{array}$ & 1999 & $\begin{array}{l}\text { Descriptivo } \\
\text { reporte de caso }\end{array}$ & $\begin{array}{l}\text { Presentación de una técnica electrónica } \\
\text { de un microchip para marcaje por } \\
\text { inclusión en prótesis de acrílico y leído } \\
\text { por un escáner }\end{array}$ & $\begin{array}{l}\text { Microchip electrónico con } \\
\text { número de identificación } \\
\text { digital }\end{array}$ \\
\hline $\begin{array}{l}\text { Borrman y } \\
\text { cols. (73) }\end{array}$ & 1999 & $\begin{array}{l}\text { Descriptivo } \\
\text { reporte de caso }\end{array}$ & $\begin{array}{l}\text { Presentación de una técnica de inclusión } \\
\text { de una etiqueta de metal grabada para } \\
\text { marcaje por inclusión en prótesis de } \\
\text { acrílico }\end{array}$ & $\begin{array}{l}\text { Etiqueta de metal en acero } \\
\text { inoxidable grabada con un } \\
\text { código de identificación }\end{array}$ \\
\hline Reeson (74) & 2001 & $\begin{array}{l}\text { Descriptivo } \\
\text { reporte de caso }\end{array}$ & $\begin{array}{l}\text { Presentación de una técnica de inclusión } \\
\text { de una etiqueta de metal grabada para } \\
\text { marcaje por inclusión en prótesis de } \\
\text { acrílico }\end{array}$ & $\begin{array}{l}\text { Etiqueta de metal en acero } \\
\text { inoxidable grabada con un } \\
\text { código de identificación }\end{array}$ \\
\hline $\begin{array}{l}\text { Matsumura y } \\
\text { Shimoe (75) }\end{array}$ & 2002 & $\begin{array}{l}\text { Descriptivo } \\
\text { reporte de caso }\end{array}$ & $\begin{array}{l}\text { Presentación de una técnica de grabado } \\
\text { bajo relieve de estructuras metálicas } \\
\text { para marcaje por inclusión en prótesis de } \\
\text { acrílico }\end{array}$ & $\begin{array}{l}\text { Bajo relieve de código de } \\
\text { identificación recubierto } \\
\text { por acrílico }\end{array}$ \\
\hline $\begin{array}{l}\text { Rajan y } \\
\text { Julián (76) }\end{array}$ & 2002 & $\begin{array}{l}\text { Descriptivo } \\
\text { observacional }\end{array}$ & $\begin{array}{l}\text { Determinar las consideraciones estéticas } \\
\text { de una técnica de marcaje por inclusión } \\
\text { de microchips grabados con códigos de } \\
\text { identificación incluidos en prótesis de } \\
\text { acrílico }\end{array}$ & $\begin{array}{l}\text { Microchips con códigos } \\
\text { de identificación grabados } \\
\text { por medios fotoquímicos }\end{array}$ \\
\hline $\begin{array}{l}\text { Ling y cols. } \\
\text { (77) }\end{array}$ & 2003 & $\begin{array}{l}\text { Descriptivo } \\
\text { reporte de caso }\end{array}$ & $\begin{array}{l}\text { Presentación de una técnica de marcaje } \\
\text { de prótesis mediante el grabado de } \\
\text { estructuras metálicas con láser de vapor } \\
\text { de cobre }\end{array}$ & $\begin{array}{l}\text { Grabado superficial de } \\
\text { códigos de identificación }\end{array}$ \\
\hline
\end{tabular}




\begin{tabular}{|c|c|c|c|c|}
\hline $\begin{array}{l}\text { Autores y } \\
\text { referencia }\end{array}$ & Año & $\begin{array}{c}\text { Tipo de } \\
\text { estudio y diseño }\end{array}$ & Propósito & $\begin{array}{c}\text { Técnica, etiqueta } \\
\text { o dispositivo }\end{array}$ \\
\hline $\begin{array}{l}\text { Millet y } \\
\text { Jeannin (78) }\end{array}$ & 2004 & $\begin{array}{l}\text { Descriptivo } \\
\text { reporte de caso }\end{array}$ & $\begin{array}{l}\text { Presentación de una técnica electrónica } \\
\text { de un microchip para marcaje por } \\
\text { inclusión en prótesis de acrílico y leído } \\
\text { por un escáner }\end{array}$ & $\begin{array}{l}\text { Microchip electrónico } \\
\text { plástico con número de } \\
\text { identificación digital }\end{array}$ \\
\hline $\begin{array}{l}\text { Thevissen y } \\
\text { cols. (79) }\end{array}$ & 2006 & $\begin{array}{l}\text { Descriptivo } \\
\text { reporte de caso }\end{array}$ & $\begin{array}{l}\text { Presentación de una técnica electrónica } \\
\text { de un microchip para marcaje por } \\
\text { implantación en una cavidad dental tipo I } \\
\text { recubierta por una restauración en resina } \\
\text { compuesta y leído por un escáner }\end{array}$ & $\begin{array}{l}\text { Microchip electrónico con } \\
\text { cápsula de vidrio con } \\
\text { número de identificación } \\
\text { digital }\end{array}$ \\
\hline $\begin{array}{l}\text { Thevissen y } \\
\text { cols. (80) }\end{array}$ & 2006 & $\begin{array}{l}\text { Descriptivo cuasi } \\
\text { experimental }\end{array}$ & $\begin{array}{l}\text { Determinar la resistencia a las altas } \\
\text { temperaturas de un microchip implantado } \\
\text { en una cavidad dental tipo I recubierta por } \\
\text { una restauración en resina compuesta }\end{array}$ & $\begin{array}{l}\text { Microchip electrónico con } \\
\text { cápsula de vidrio con } \\
\text { número de identificación } \\
\text { digital }\end{array}$ \\
\hline $\begin{array}{l}\text { Murray y } \\
\text { cols. (22) }\end{array}$ & 2007 & $\begin{array}{l}\text { Descriptivo } \\
\text { reporte de caso }\end{array}$ & $\begin{array}{l}\text { Determinar la prevalencia del uso de } \\
\text { prótesis acrílicas etiquetadas con códigos } \\
\text { con fines de identificación del paciente } \\
\text { incluidas en prótesis de acrílico }\end{array}$ & $\begin{array}{l}\text { Etiquetas de diferentes } \\
\text { materiales impresas con } \\
\text { un código de identificación }\end{array}$ \\
\hline $\begin{array}{l}\text { Takahashi y } \\
\text { cols. (81) }\end{array}$ & 2008 & $\begin{array}{l}\text { Descriptivo cuasi } \\
\text { experimental }\end{array}$ & $\begin{array}{l}\text { Comparación de la resistencia de tres } \\
\text { métodos de marcaje químico superficial } \\
\text { de prótesis acrílicas }\end{array}$ & $\begin{array}{l}\text { Etiquetas de papel } \\
\text { impresas con un código de } \\
\text { identificación recubiertas } \\
\text { con resina acrílica de } \\
\text { autopolimerización, } \\
\text { resina acrílica de } \\
\text { fotopolimerización y } \\
\text { adhesivo a base de resina }\end{array}$ \\
\hline $\begin{array}{l}\text { Agüloğlu y } \\
\text { cols. (33) }\end{array}$ & 2009 & $\begin{array}{l}\text { Descriptivo } \\
\text { reporte de caso }\end{array}$ & $\begin{array}{l}\text { Presentación de una técnica de inclusión } \\
\text { de una etiqueta de papel impresa para } \\
\text { marcaje por inclusión en prótesis de } \\
\text { acrílico }\end{array}$ & $\begin{array}{l}\text { Etiqueta de papel impresa } \\
\text { con un código de barras }\end{array}$ \\
\hline $\begin{array}{l}\text { Anehosur y } \\
\text { cols. (82) }\end{array}$ & 2009 & $\begin{array}{l}\text { Descriptivo } \\
\text { reporte de caso }\end{array}$ & $\begin{array}{l}\text { Presentación de una técnica de inclusión } \\
\text { de una etiqueta de papel impresa para } \\
\text { marcaje por inclusión en prótesis de } \\
\text { acrílico }\end{array}$ & $\begin{array}{l}\text { Etiqueta de papel impresa } \\
\text { con un código de barras o } \\
\text { fotografía del paciente }\end{array}$ \\
\hline $\begin{array}{l}\text { Richmond y } \\
\text { cols. (3) }\end{array}$ & 2009 & $\begin{array}{l}\text { Descriptivo cuasi } \\
\text { experimental }\end{array}$ & $\begin{array}{l}\text { Determinar la resistencia de etiquetas } \\
\text { incluidas en prótesis acrílicas expuestas a } \\
\text { medios ambientes hostiles }\end{array}$ & $\begin{array}{l}\text { Etiqueta de papel impresa } \\
\text { con un código de } \\
\text { identificación }\end{array}$ \\
\hline $\begin{array}{l}\text { Bansal y } \\
\text { cols. (83) }\end{array}$ & 2011 & $\begin{array}{l}\text { Descriptivo } \\
\text { reporte de caso }\end{array}$ & $\begin{array}{l}\text { Presentación de una técnica de inclusión } \\
\text { de una etiqueta de papel de plomo } \\
\text { impresa para marcaje por inclusión en } \\
\text { prótesis de acrílico }\end{array}$ & $\begin{array}{l}\text { Etiqueta de papel de } \\
\text { plomo grabado en bajo } \\
\text { relieve con un código de } \\
\text { barras recubierta con } \\
\text { resina acrílica }\end{array}$ \\
\hline $\begin{array}{l}\text { Nalawade y } \\
\text { cols. (84) }\end{array}$ & 2011 & $\begin{array}{l}\text { Descriptivo } \\
\text { reporte de caso }\end{array}$ & $\begin{array}{l}\text { Presentación de una técnica de inclusión } \\
\text { de una etiqueta de papel impresa para } \\
\text { marcaje por inclusión en prótesis de } \\
\text { acrílico }\end{array}$ & $\begin{array}{l}\text { Etiqueta de papel impresa } \\
\text { con un código de barras }\end{array}$ \\
\hline $\begin{array}{l}\text { Acharya y } \\
\text { cols. }(40)\end{array}$ & 2011 & $\begin{array}{l}\text { Descriptivo } \\
\text { cualitativo }\end{array}$ & $\begin{array}{l}\text { Creencias, prácticas y actitudes sobre el } \\
\text { marcaje de prótesis acrílicas por inclusión } \\
\text { en prótesis de acrílico }\end{array}$ & $\begin{array}{l}\text { Etiquetas con un código } \\
\text { de identificación }\end{array}$ \\
\hline
\end{tabular}




\begin{tabular}{|c|c|c|c|c|}
\hline $\begin{array}{l}\text { Autores y } \\
\text { referencia }\end{array}$ & Año & $\begin{array}{c}\text { Tipo de } \\
\text { estudio y diseño }\end{array}$ & Propósito & $\begin{array}{c}\text { Técnica, etiqueta } \\
\text { o dispositivo }\end{array}$ \\
\hline $\begin{array}{l}\text { Madrid y } \\
\text { cols. (36) }\end{array}$ & 2012 & $\begin{array}{l}\text { Descriptivo } \\
\text { reporte de caso }\end{array}$ & $\begin{array}{l}\text { Presentación de una técnica electrónica } \\
\text { de un microchip para marcaje por } \\
\text { inclusión en prótesis de acrílico y leído } \\
\text { por un escáner }\end{array}$ & $\begin{array}{l}\text { Microchip electrónico } \\
\text { plástico con número de } \\
\text { identificación digital }\end{array}$ \\
\hline $\begin{array}{l}\text { Luthra y col. } \\
\text { (85) }\end{array}$ & 2012 & $\begin{array}{l}\text { Descriptivo } \\
\text { reporte de caso }\end{array}$ & $\begin{array}{l}\text { Presentación de una técnica electrónica } \\
\text { de un memoria SD para marcaje por } \\
\text { inclusión en prótesis de acrílico y leído } \\
\text { por un escáner }\end{array}$ & $\begin{array}{l}\text { Memoria SD con } \\
\text { información digitalizada } \\
\text { del paciente }\end{array}$ \\
\hline $\begin{array}{l}\text { Mahoorkar y } \\
\text { Jain (86) }\end{array}$ & 2013 & $\begin{array}{l}\text { Descriptivo } \\
\text { reporte de caso }\end{array}$ & $\begin{array}{l}\text { Presentación de una técnica de inclusión } \\
\text { de una etiqueta de papel impresa para } \\
\text { marcaje por inclusión en prótesis de } \\
\text { acrílico }\end{array}$ & $\begin{array}{l}\text { Etiqueta de papel impresa } \\
\text { con un código de barras }\end{array}$ \\
\hline $\begin{array}{l}\text { Sudheendra } \\
\text { y cols. (87) }\end{array}$ & 2013 & $\begin{array}{l}\text { Descriptivo } \\
\text { reporte de caso }\end{array}$ & $\begin{array}{l}\text { Presentación de una técnica de inclusión } \\
\text { de una etiqueta de papel impresa para } \\
\text { marcaje por inclusión en prótesis de } \\
\text { acrílico }\end{array}$ & $\begin{array}{l}\text { Etiqueta de papel impresa } \\
\text { con un código } 2 \mathrm{D} \text { de } \\
\text { barras }\end{array}$ \\
\hline $\begin{array}{l}\text { Aragón y } \\
\text { cols. (88) }\end{array}$ & 2013 & $\begin{array}{l}\text { Descriptivo cuasi } \\
\text { experimental }\end{array}$ & $\begin{array}{l}\text { Determinar la resistencia compresiva de } \\
\text { un microchip implantado en cavidades } \\
\text { dentales tipo I y tipo IV recubiertas por } \\
\text { una restauración en resina compuesta }\end{array}$ & $\begin{array}{l}\text { Microchip electrónico con } \\
\text { cápsula de vidrio de uso } \\
\text { en humanos con número } \\
\text { de identificación digital }\end{array}$ \\
\hline $\begin{array}{l}\text { Moreno y } \\
\text { cols. (89) }\end{array}$ & 2013 & $\begin{array}{l}\text { Descriptivo cuasi } \\
\text { experimental }\end{array}$ & $\begin{array}{l}\text { Determinar la resistencia a las altas } \\
\text { temperaturas de un microchip implantado } \\
\text { en cavidades dentales tipo I y tipo IV } \\
\text { recubiertas por una restauración en resina } \\
\text { compuesta }\end{array}$ & $\begin{array}{l}\text { Microchip electrónico con } \\
\text { cápsula de vidrio de uso } \\
\text { en humanos con número } \\
\text { de identificación digital }\end{array}$ \\
\hline
\end{tabular}

FIGURA 1

FRECUENCIA DE REPORTES SOBRE LAS TÉCNICAS, ETIQUETAS Y DISPOSITIVOS EMPLEADOS EN EL MARCAJE DE PRÓTESIS DENTALES

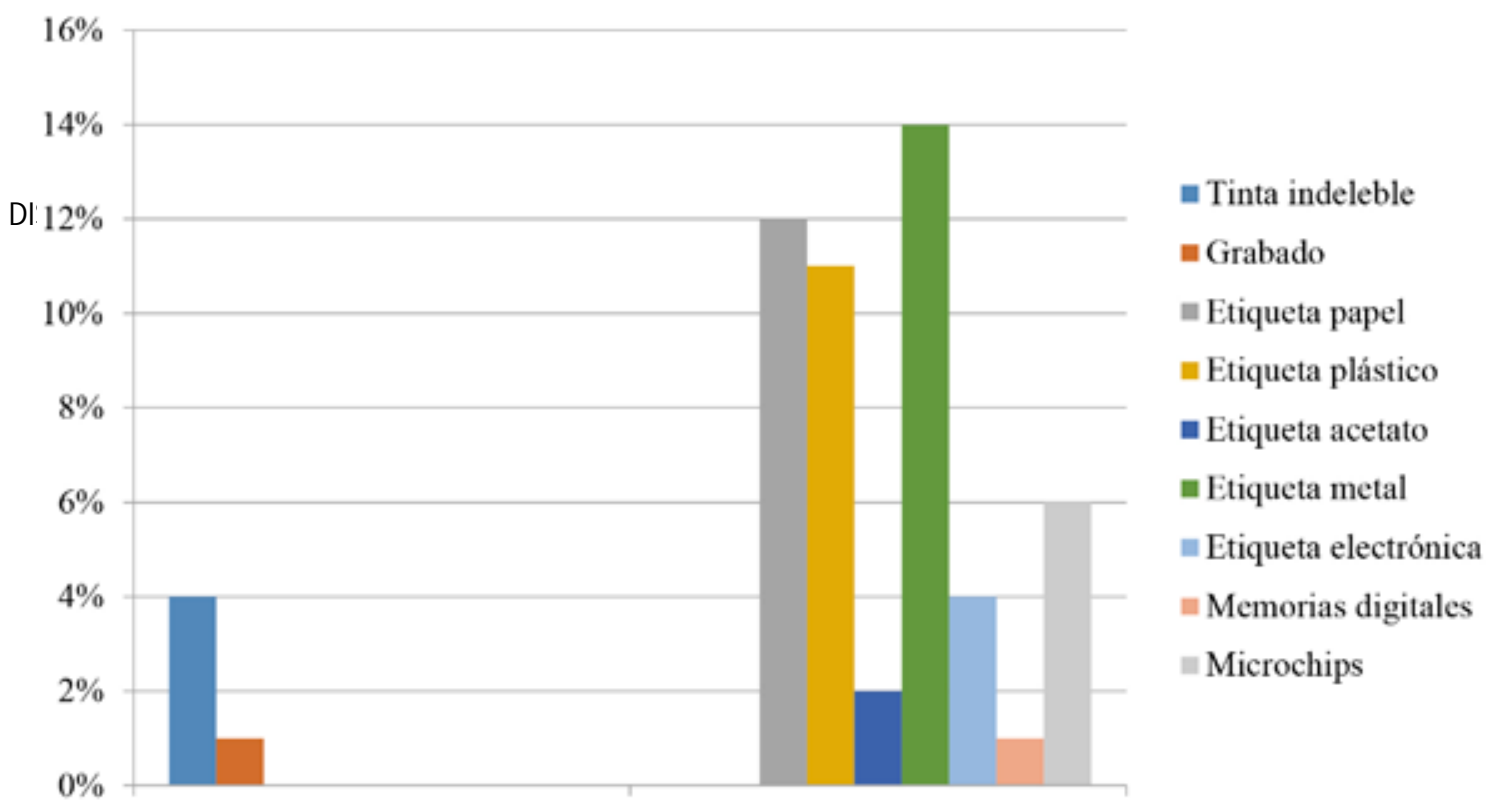

Téenica de marcaje superficial Téenica de marcaje por inclusión 
De acuerdo con lo reportado en la literatura, la mayoría de estudios se han centrado en el reporte de diversas técnicas, etiquetas y dispositivos para el marcaje de prótesis dentales. Solo unos pocos realmente se han concentrado en determinar qué tipo de dispositivo es realmente el más eficiente en el momento de cumplir con los requisitos de resistencia, permanencia y estética. Al analizar la tabla 1 se pueden observar tres momentos en la evolución de las técnicas de marcaje. En un primer momento (entre 1958 y 1980) surge la necesidad de emplear las prótesis dentales como medios para identificar las personas dentro del contexto forense a partir de su marcaje, con base en que la mitad de la población era total o parcialmente edéntula, y que precisamente con la ausencia de los dientes naturales se perdían los marcadores habituales de uso en los procedimientos de identificación odontológica (3).

En un segundo momento (1980 a 1990) se plantea la necesidad de estandarizar las técnicas de marcaje, debido a que en ciertos países se lograron identificar individuos edéntulos a partir de sus prótesis dentales (3). Se desarrolló en Suecia el sistema ID-Band, que consiste en una banda metálica grabada con un código de identificación (representación de la identidad del paciente) que se incluye en el acrílico de las prótesis dentales. Con esta técnica se establecieron los requisitos mínimos que deben seguir una etiqueta o dispositivo de marcaje: resistencia y permanencia ante medios hostiles, inalterabilidad de la estética y resistencia de la prótesis y biocompatibilidad con el medio oral. Además, se incluyen bajo costo y facilidad de lectura (59,90,91). La ADA desarrolló en 1982 una técnica de marcaje a través de un microdisco acrílico (azul para hombre y rosado para mujeres), no solo para individuos edéntulos (a través de sus prótesis dentales), sino también para individuos dentados (cementado en la superficie vestibular del primer molar superior derecho). Este nunca fue reglamentado $(53,54)$, razón por la cual los esfuerzos por emplear el marcaje de prótesis no ha dejado de ser, tal como se mencionó, un esfuerzo local de diferentes organizaciones académicas y científicas odontológicas, especialmente las forenses (92).

Por último, en un tercer momento (2000 a la actualidad), a la par de los avances tecnológicos, diversos reportes han sugerido emplear, mediante la técnica de inclusión, etiquetas de papel con códigos de barras y códigos de barras 2D, que permitan ser leídas a través de un escáner para acceder a una base de datos con la información de paciente. Si bien este sistema no es tan costoso como se podría pensar, está en entredicho la resistencia a las altas temperaturas, lo que disminuye la eficacia, no de la técnica, sino de la etiqueta per se $(33,86,87)$. Del mismo modo, diferentes autores se han apropiado de la tecnología de identificación por radiofrecuencia y han propuesto implantar microchips en las prótesis dentales (36,76-78). Sin embargo, y pese a que siempre existe esta posibilidad con el método de marcaje de prótesis, estas se pueden desadaptar durante los fenómenos biológicos cadavéricos, como la esqueletización, que acontecen post mórtem y pueden perderse en el lugar donde se encuentran los restos humanos (27). Por dicha razón, algunos autores han realizado estudios que evalúan la posibilidad de implantación de los microchips en cavidades de los dientes restaurados con materiales a base de resina $(79,80)$. Esto se debe a que la Administración de Comidas y Medicinas de Estados Unidos aprobó la implantación de estos dispositivos pasivos en el cuerpo humano, pese a que resultan evidentes los inconvenientes clínicos de la conformación de un granuloma en el tejido conectivo como respuesta a una reacción a cuerpo extraño y su asociación como mecanismo de lesiones neoplásicas. Además, existe el mismo inconveniente de la pérdida del microchip durante los fenómenos cadavéricos a los que se hizo mención anteriormente $(88,89)$.

Por todo lo anterior, y pese a que la discusión sobre el marcaje de las prótesis dentales lleva poco más de 50 años sin llegar a un consenso, es importante resaltar la evidencia científica disponible y el papel que tiene la odontología dentro de las ciencias forenses. Por ello, cualquier elemento, bien sea diagnóstico o bien terapéutico, que se constituya en un marcador que permita la identificación de un individuo o sus restos humanos debe ser considerado, investigado y puesto a disposición de las entidades e instituciones competentes para ser empleado en dichos procedimientos (93).

\section{CONCLUSIONES}

Las técnicas, las etiquetas y los dispositivos para marcar prótesis dentales se constituyen en una herramienta invaluable que se comportaría como una prueba indiciaria para guiar la búsqueda de información ante mórtem con el propósito de hacer el cotejo post mórtem a partir de marcadores que permitan identificar positiva y absolutamente a un individuo o sus restos humanos durante los procesos de identificación odontológica y documentación de la necropsia médico-legal. 
Debido a la situación de orden público que existe en países como Colombia, donde existe además una alta prevalencia de edentulismo y uso de prótesis dentales, y teniendo como referencia toda la evidencia científica disponible, resulta plausible implementar técnicas, etiquetas y dispositivos para marcar dichas prótesis con fines de identificación forense. Para ello, las entidades competentes como la Federación Odontológica Colombiana, la Asociación Colombiana de Facultades de Odontología y la Fiscalía General de la Nación, a través del Cuerpo Técnico Investigativo y del Instituto Nacional de Medicina Legal y Ciencias Forenses, deben trabajar conjuntamente en la reglamentación de leyes como la 38 de 1993, por la cual se unifica el sistema de dactiloscopia y se adopta la carta dental para fines de identificación.

Se debe implementar un protocolo estandarizado con base en normas internacionales, a fin de determinar la mejor técnica, etiqueta y dispositivo para marcar las prótesis dentales de acuerdo con los criterios de permanencia: resistencia a situaciones hostiles (salinidad, alcalinidad, impacto y altas y bajas temperaturas), inalterabilidad de la prótesis (estética, resistencia y adaptación), costo favorable, fácil lectura (sin necesidad de destruir, alterar o modificar la prótesis), biocompatibilidad y aceptación de los pacientes con base en sus creencias, prácticas y actitudes.

\section{AGRADECIMIENTOS}

Esta revisión sistemática de la literatura deriva del proyecto de investigación Cambios tisulares producidos por la implantación subcutánea de un microchip de identificación por radiofrecuencia pasivo recubierto con Parylene C@ en rata Wistar, el cual fue financiado por la convocatoria interna de la Vicerrectoría de Investigaciones de la Universidad del Valle, Cali, Colombia.

\section{REFERENCIAS}

1. Rodríguez JV. La antropología forense en la identificación humana. Bogotá: Universidad Nacional de Colombia; 2004.

2. Marín L, Moreno F. Odontología forense. En: Enciclopedia criminalística, criminología e investigación. $1^{\mathrm{a}}$ ed. Bogotá: Sigma; 2010. pp. 733-76.

3. Richmond R, Phil M, Pretty IA. A range of postmortem assault experiments conducted on a variety of denture labels used for the purpose of identification of edentulous individuals. J Forensic Sci. 2009; 54(2): 411-4.

4. República de Colombia. Ley 38 del 15 de enero de 1993 , por la cual se unifica el sistema de dactiloscopia y se adopta la carta dental para fines de identificación. Diario Oficial 40.724.

5. Casas JA, Narváez H, Rodríguez JV, Valdés Y. Odontología forense. $1^{\mathrm{a}}$ ed. Bogotá: Ecoe; 1995.

6. Hunt RJ, Beck JD, Lemke JH, Kohout FJ, Wallace RB. Edentulism and oral health problems among elderly rural lowans: the lowa 65+ rural health study. Am J Public Health. 1985; 75(10): 1177-81.

7. Takala L, Utriainen P, Alanen P. Incidence of edentulousness, reasons for full clearance, and health status of teeth before extractions in rural Finland. Community Dent Oral Epidemiol. 1994; 22(4): 254-7.

8. Suominen-Taipale AL, Alanen P, Helenius H, Nordblad A, Uutela A. Edentulism among Finnish adults of working age, 1978-1997. Community Dent Oral Epidemiol. 1999; 27(5): 353-65.

9. Flemming C, Torres S, Marino M. Perfil epimediologico de caries e do uso e necessidade de prótese da população idosa de Biguaçu, Santa Catalina. Rev Bras Epimediol. 2004; 7(1): 88-97.

10. Beltrán-Aguilar ED, Barker LK, Canto MT, Dye BA, Gooch BF, Griffin SO, Hyman J, Jaramillo F, Kingman A, Nowjack-Raymer R, Selwitz RH, Wu T, Centers for Disease Control and Prevention (CDC). Surveillance for dental caries, dental sealants, tooth retention, edentulism, and enamel fluorosis--United States, 1988-1994 and 19992002. MMWR Surveill Summ. 2005; 54(3): 1-43.

11. República de Colombia, Ministerio de Salud. Tercer Estudio Nacional de Salud Bucal (ENSAB III). Tomo VII. Estudio Nacional de Salud Bucal. Bogotá: Ministerio de Salud; 1999.

12. Steele J, Treasure E. Total tooth loss in the United Kingdom in 1998 and the implications for the future. Brit Dent J 2000; 189: 598-603.

13. Harwood $\mathrm{L}$. The evidence base for current practices in prosthodontics. Eur J Prosthodontics Rest Dent. 2008; 16(1): 24-34.

14. Guerra A. Odontoestomatología forense. $1^{\mathrm{a}}$ edición. Bogotá: Ecoe; 2002.

15. Orjuela CE. Odontología forense. En: Téllez NR, editor. Medicina forense: manual integrado. Bogotá: Universidad Nacional de Colombia; 2002.

16. Orjuela CE, Duque MA, Velosa G, Carreño MI, Constantín AE. Guía práctica para el dictamen odontológico forense y de dictamen de edad. $1^{\text {a }}$ ed. Bogotá: Instituto Nacional de Medicina Legal y Ciencias Forenses; 2004.

17. Rothwell BR. Principios de la identificación odontológica. En: Fixot RH, editor. Clínicas odontológicas de Norteamérica: odontología forense. México: Interamericana; 2001. pp. 259-73.

18. Mertz CA. Identificación dental. En: Standish SM, Stimson PG, directores. Clínicas odontológicas de Norteamérica: odontología forense. México: Interamericana; 1977. pp. 47-67.

19. American Board of Forensic Odontology ABFO. Body identification guidelines. J Am Dent Assoc. 1994; 125(9): 1244-54. 
20. Marín NL, Moreno F. Odontología forense: identificación odontológica, reporte de casos. Rev Estomatol. 2003: 11(2): 41-9.

21. Fletcher AM, Turner CH, Ritchie GM. Denture marking methods and induced stress. Br Dent J. 1977; 142: 224-6.

22. Murray CA, Boyd PT, Young BC, Dhar S, Dickson M, Currie JNW. A survey of denture identification marking within the United Kingdom. Br Dent J. 2007; 203(24): 1-5.

23. Haines $\mathrm{DH}$. Identification in mass disasters from dental prostheses. Int J Forensic Dent. 1973; 1: 11-5.

24. Marín NL, Moreno F. Odontología forense: identificación odontológica de individuos quemados, reporte de dos casos. Rev Estomatol. 2004; 12(2): 57-70.

25. Richmond R, Phil M, Pretty IA. Contemporary methods of labeling dental prostheses. A review of the literature. J Forensic Sci. 2006; 51(5): 1338-42.

26. Gosavi S, Gosavi S. Forensic odontology: A prosthodontic view. J Forensic Dent Sci. 2012; 4: 38-41.

27. Moreno F, Moreno S, Marín L. Identificación odontológica forense: revisión de la literatura y reporte de un caso. USTA Salud Odontol. 2007; 6: 60-6.

28. Vestermark J. Identification from dental disaster. Int J Forensic Dent. 1975; 3: 3-6.

29. Luthra R, Arora S, Meshram S. Denture marking for forensic identification using memory card: An innovative technique. J Indian Prosthodont Soc. 2012; 12(4): 231-4.

30. Turner $\mathrm{CH}$, Fletcher AM, Ritchie GM. Denture marking and human identification. Br Dent J. 1976; 141(4): 114-7.

31. Padmanabhan TV, Gupta RK. Denture marking: an introduction and review. J Forensic Dent Sci. 2009; 1(1): 11-6.

32. Mohan J, Kumar CD, Simon P. Denture marking as an aid to forensic identification. J Indian Prosthodont Soc. 2012; 12(3): 131-6.

33. Agüloğlu $\mathrm{S}$, Zortuk M, Beydemir K. Denture barcoding: a new horizon. Br Dent J. 2009; 206(11): 589-90.

34. Sudheendra US, Sowmya K, Vidhi M, Shreenivas K, Prathamesh J. 2D barcodes: D novel and simple method for denture identification. J Forensic Sci. 2013; 58(1): 170-2.

35. Millet C, Jeannin C. Incorporation of microchips to facilitate denture identification by radiofrequency tagging. J Prosthet Dent. 2004; 92: 588-90.

36. Madrid C, Korsvold T, Rochat A, Abarca M. Radio frequency identification (RFID) of dentures in long-term care facilities. J Prosthet Dent. 2012; 107: 199-202.

37. Cunningham M, Hoad-Reddick G. Attitudes to identification of dentures: the patients' perspective. Quintessence Int. 1993; 24(4): 267-70.

38. Borrman HI, Rene N. Denture marking: a questionnaire for patients and dentists. J Forensic Odontostomatol. 1997; 8: 3-10.

39. Richmond R, Phil M, Pretty IA. Denture marking: Patient preference of various methods. J Forensic Sci. 2007; 52(6): 1338-42.

40. Acharya AB, Anehosur GV, Kanchi PP, Naik MG, Nadiger RK. Perceptions and references on denture marking in an Indian Sample. Gerodontol. 2012; 29: 117-24.
41. Lose FM. Denture identification. J Prosthet Dent. 1958; 8: 940.

42. Todo J, Lukens EM. A technique for placing names in dentures. J Prosthet Dent. 1977; 37(4): 469-71.

43. MacEntee Ml, Campbell T. Personal identification using dental prosthesis. J Prosthet Dent. 1979; 41: 377-80.

44. Thomas CJ. The marking of dentures. J Dent Assoc S Afr. 1980; 35(1): 21-2.

45. Gladfelter IA, Smith BE. An evaluation of microdisk for dental identification. J Prosthetic Dent. 1989; 62(3): 352-5.

46. Hansen RW. Intraoral micro-identification discs. J Forensic Odontostomatol. 1991; 9(2): 77-91.

47. Johanson G, Ekman B. Denture marking. J Am Dent Assoc. 1984; 108(3): 347-50.

48. Luebke RJ, Unsicker RL. Denture identification using heat shrunk plastic strips. lowa Dent J. 1985; 71(4): 39-40.

49. Dippenaar AP. Denture marking: an aesthetic inclusion technique. J Dent Assoc S Afr. 1986; 41: 13.

50. Chalian VA, Sayoc AM, Ghalichebaf M, Schaeffer L. Identification of removable dental prosthesis. J Prosthet Dent. 1986; 56(2): 254-6.

51. Fiske J, Graham T, Gelbier S. Denture identification for elderly people. Br Dent J. 1986; 161(12): 448-9.

52. Young KL. On-site denture identification can be a practice-builder. Dent Econ. 1987; 77(5): 68-70.

53. Stevenson RB. Marking dentures for identification. J Prosthet Dent. 1987; 58(2): 255.

54. Heath JR. Denture identification: A simple approach. J Oral Rehabil. 1987; 14(2): 147-63.

55. Heath JR, Zoitopoulos L, Griffiths C. Simple methods for denture identification: a clinical trial. J Oral Rehabil. 1988; 15(6): 587-92.

56. Toolson LB, Taylor TD. Method for denture identification. J Prosthet Dent. 1989; 61(1): 114-5.

57. Oliver B. A new inclusion denture marking system. Quintessence Int. 1989; 20(1): 21-5.

58. Lamb DJ. A simple method for permanent identification of dentures. J Prosthet Dent. 1992; 67(6): 894.

59. Olsson T, Thureson P, Borrman H. Denture marking. A study of temperature resistance of different metal bands for ID-marking. J Forensic Odontostomatol. 1993 Dec; 11(2): 37-44.

60. Ling BC. A white character denture labelling technique. J Prosthet Dent. 1993; 69(5): 545.

61. Ryan LD, Keller JB, Rogers DE, Schaeffer L. Clear acrylic resin T-bar used in denture identification. J Prosthet Dent. 1993; 70(2): 189-90.

62. Borrman H, Thomas CJ, Engstrom EU. Denture marking. Clinical and technical aspects. J Forensic Odontostomatol. 1995; 13(1): 14-7.

63. Thomas CJ, Mori T, Miyakawa O, Chung HG. In search of a suitable denture marker. J Forensic Odontostomatol. 1995; 13(1): 9-13.

64. Berry FA, Logan Gl, Plata R, Riegel R. A postfabrication technique for identification of prosthetic devices. J Prosthet Dent. 1995; 73(4): 341-3. 
65. Coss P, Wolfaardt JF. Denture identification system. J Prosthet Dent. 1995; 74(5): 551-2.

66. Bengtsson A, Olsson T, Rene N, Carlsson GE, Dahlbom U, Borrman $\mathrm{H}$. Frequency of edentulism and identification marking of removable dentures in long-term care units. J Oral Rehabil. 1996; 23(8): 520-3.

67. Milward PJ, Shepherd P, Brickley MR. Automatic identification of dental appliances. Br Dent J. 1997; 182: 171-4.

68. Bernitz $\mathrm{H}$, Blignaut J. An inclusion technique for marking dentures. J Forensic Odontostomatol. 1998; 16(1): 14-6.

69. Stenberg I, Borrman HI. Dental condition and identification marking of dentures in homes for the elderly in Göteborg, Sweden. J Forensic Odontostomatol. 1998; 16(2): 35-7.

70. Ibrahim WM. Denture microlabeling technique. J Prosthet Dent. 1996; 76(1): 104.

71. Ling BC. Computer-printer denture microlabeling system. J Prosthet Dent. 1998; 79(3): 363-4.

72. Rötzscher K, Bedrich MR, Jurisch R, Peitsch P. Electronic denture marking: An aid for identification. J Forensic Odontostomatol. 1999; 17(1): 27-9.

73. Borrman HI, DiZinno JA, Wasén J, René N. On denture marking. J Forensic Odontostomatol. 1999; 17(1): 20-6.

74. Reeson MG. A simple and inexpensive inclusion technique for denture identification. J Prosthet Dent. 2001; 86(4): 441-2.

75. Matsumura H, Shimoe S. Incorporation of a cast, embossed identification plate into a partial denture framework. J Prosthet Dent. 2002; 88: 215-7.

76. Rajan M, Julian R. A new method of marking dentures using microchips. J Forensic Odontostomatol. 2002; 20(1): 1-5.

77. Ling BC, Nambiar P, Low KS, Lee CK. Copper vapour laser ID labeling on metal dentures and restorations. J Forensic Odontostomatol. 2003; 21(1): 17-22.

78. Millet C, Jeannin C. Incorporation of microchips to facilitate denture identification by radio frequency tagging. J Prosthet Dent. 2004; 92(6): 588-90.

79. Thevissen PW, Poelman G, De Cooman M, Puers R, Willems $\mathrm{G}$. Implantation of an RFID-tag into human molars to reduce hard forensic identification labor. Part I: Working principle. Forensic Sci Int. 2006; 159(suppl 1): 33-9.

80. Thevissen PW, Poelman G, De Cooman M, Puers R, Willems G. Implantation of an RFID-tag into human molars to reduce hard forensic identification labor. Part 2: Physical properties. Forensic Sci Int. 2006; 159(suppl 1): 40-6.

81. Takahashi F, Koji T, Morita O. A new method for denture identification. Dent Mater J. 2008; 27(2): 278-83.

82. Anehosur GV, Acharya AB, Nadiger RK. Usefulness of patient photograph as a marker for identifying denturewearers in India. Gerodontol. 2010; 27: 272-7.

83. Bansal PK, Sharma A, Bhanot R. Denture labeling: A new approach. Contemp Clin Dent. 2011; 2: 76-8.

84. Nalawade SN, Lagdive SB, Gangadhar SA, Bhandari AJ. A simple and inexpensive bar-coding technique for denture identification. J Forensic Dent Sci. 2011; 3(2): 92-4.
85. Luthra R, Arora S, Meshram. Denture marking for forensic identification using memory card: An innovative technique. J Indian Prosthodont Soc. 2012; 12(4): 231-5.

86. Mahoorkar S, Jain A. Denture identification using unique identification authority of India barcode. J Forensic Dent Sci. 2013; 5: 60-3

87. Sudheendra US, Sowmya K, Vidhi M, Shreenivas K, Prathamesh J. 2D Barcodes: A novel and simple method for denture identification. J Forensic Sci. 2013; 58(1): 170-2.

88. Aragón N, Moreno F, Salazar L. In vitro behavior of interfaces in human molars with an implanted passive RFID microchip and subjected to compression forces. DYNA. 2013; 80(178): 5-10.

89. Moreno F, Vallejo D, Garzón H, Moreno S. In vitro evaluation of a passive radio frequency identification microchip implanted in human molars subjected to compression forces, for forensic purposes of human identification. $J$ Forensic Dent Sci. 2013; 5: 77-84.

90. Thomas CJ. The role of the denture in identification: a review. J Forensic Odontostomatol. 1984; 2: 13-6.

91. Stavrianos C, Stavrianou I, Kafas P. Denture identification system based on Swedish guidelines: a forensic aspect. Internet J Forensic Sci. 2008; 3(1): 1-4.

92. Mohan J, Kumar CD, Simon P. Denture marking as an aid to forensic identification. Indian Prosthodont Soc. 2012; 12(3): 131-6.

93. Datta $\mathrm{P}$, Sood $\mathrm{S}$. The various methods and benefits of denture labeling. J Forensic Dent Sci. 2010; 2(2): 53-8.

\section{CORRESPONDENCIA}

\author{
Sebastián Medina \\ sebastianmedina.c@gmail.com \\ Diego Vallejo \\ dvallejob@hotmail.com \\ Freddy Moreno Gómez \\ freddy.a.moreno@correounivalle.edu.co \\ fmorenog@javerianacali.edu.co
}

